\title{
Timing of Change in Criminal Offending Around Entrance into Parenthood: Gender and Cross-Country Comparisons for At-Risk Individuals
}

\author{
Mioara Zoutewelle-Terovan ${ }^{1} \cdot$ Torbjorn Skardhamar $^{2}$
}

Published online: 21 January 2016

(C) The Author(s) 2016. This article is published with open access at Springerlink.com

\begin{abstract}
Objectives This article examines the timing of change in criminal offending relative to entrance into parenthood, in light of four competing theoretical frameworks (social control, routine activities, strain and cognitive transformation). Moreover, it analyzes whether criminal developments over time are gender- or country-specific.

Methods Using samples of men and women at risk of offending in the Netherlands and Norway, this study investigates monthly changes in offending probabilities around the time of first birth (5 years before, 5 years after). The implemented smoothing splines technique allowed for a flexible exploration of changes in offending probabilities for both prechildbirth and post-childbirth periods.

Results The results show that the probabilities to offend decline ahead of childbirth for all individuals analyzed. The post-childbirth period is characterized by increases in offending probabilities. However, in these overall trends, the exact timing and magnitude of change differs by gender and country of residence.

Conclusions The results offer partial support for the cognitive transformation hypothesis because offending rates decline before childbirth. The post-childbirth period converges with assumptions of the strain theory (for males in particular) because offending probabilities increase in this period. Additional analysis investigating changes in property offending shows that economic strain does not explain the upward trend of the overall offending after childbirth.
\end{abstract}

Keywords Life-course - Parenthood - Criminal offending · Timing of change · Competing hypotheses

Mioara Zoutewelle-Terovan

mioaraterovan@yahoo.com

1 Netherlands Interdisciplinary Demographic Institute (NIDI), P.O. Box 11650, 2502 AR The Hague, The Netherlands

2 Research Department, Statistics Norway, Oslo, Norway 


\section{Introduction}

The highly influential theory of age-graded social control (Sampson and Laub 1993; Laub and Sampson 2003) suggests that adult transitions have the potential to modify a criminal trajectory toward desistance. Of the family-related transitions, marriage received the most attention (e.g. Sampson et al. 2006; King et al. 2007; Bersani et al. 2009; Theobald and Farrington 2009). Although less empirically studied, other transitions such as becoming a parent are reported as being potentially equally important (Laub and Sampson 2003, p. 135). However, few empirical studies have analyzed the transition to parenthood (Edin et al. 2004; Giordano et al. 2002; Savolainen 2009; Monsbakken et al. 2013; De Goede et al. 2011).

The effect of parenthood on crime is expected to work through mechanisms similar to those of marriage because becoming a parent has broad consequences on family life, leisure activities, and perception of self, leading toward a conventional lifestyle (Laub and Sampson 2003). Conversely, parenthood might also lead to increased economic responsibilities that can represent a source of stress that can stimulate engagement in crime (Broidy and Agnew 1997). More specifically, increased economic responsibilities and needs could be considered incentives for illegal earnings in the context of limited lawabiding alternatives.

Previous research has shown gender differences in the effects of family-related transitions on crime (Rhule-Louie and McMahon 2007; Zoutewelle-Terovan et al. 2012). To a limited extent, the literature suggests that gender differences also apply to the parenthoodoffending relationship (Graham and Bowling 1995; Giordano et al. 2002; De Goede et al. 2011). Although modern society is characterized by less gender inequality in the division of domestic labor (including child-rearing activities), a certain level of inequality continues to exist between genders (Feeney 2001). Hence, parenthood might have a stronger influence on females, who often remain the primary caregivers for children.

Existing theoretical frameworks explaining the effects of parenthood on crime also assumed context universality. However, inconsistent empirical results shown in various studies (Blokland and Nieuwbeerta 2005; Giordano et al. 2002; Savolainen 2009; Uggen and Kruttschnitt 1998) raise two important questions: are there contextual differences, or are the dissimilarities related to differences in samples and methods. In other words, understanding whether theories apply differently in various social contexts is important. To answer such questions properly, one needs cross-national comparisons using similar designs and methods of investigation across countries.

In this study, we analyze changes in criminal trajectories in relation to entrance into parenthood. Moreover, using data from the Netherlands and Norway, our comparative design addresses whether the conclusions hold in two different social contexts. The analytic approach focuses on the timing of change around entrance into parenthood as has previously been done for marriage (Laub et al. 1998; Duncan et al. 2006; Lyngstad and Skardhamar 2013) and employment (Skardhamar and Savolainen 2014). We aim to answer the following research questions:

RQ1 How does the likelihood of offending change after the birth of the first child compared with the pre-childbirth period?

RQ2 Are the trends in offending around entrance into parenthood different for males and females? 
RQ3 Do the trends for males and females differ across social contexts in the Netherlands and Norway?

\section{Theoretical Background}

According to the age-graded theory of social control (Sampson and Laub 1993, p. 8; Laub and Sampson 2003, p. 135), becoming a parent represents a transformative event in which social bonds discourage engagement in crime. Many of the same mechanisms that make other life-course transitions potential turning points might also apply to the transition to parenthood, effectively cutting off the past from the present. For example, the parental role is associated with a set of non-criminal expectations from the network (family, peers, and social institutions), and, even more strongly than for marriage, this social network might be more critical to offending. In addition, parenting offers an opportunity to transform one's identity and has the potential to promote a non-criminal lifestyle.

From the perspective of routine activities theory, a direct influence of parenthood on offending occurs due to drastic changes in the daily routines associated with child-rearing activities and other parental responsibilities. In essence, by increasing the amount of time spent within the family, previous lifestyles and circumstances promoting offending diminish or disappear (Cohen and Felson 1979; Horney et al. 1995). Regardless of whether parental roles lead to a change in one's sense of self or represent a matter of time budget, these changes have the potential to restrain individuals from crime (Osgood et al. 1996; Warr 1998). Although the quantitative analysis of Sampson and Laub (2003) did not provide support for the effects of parenthood on offending, the narratives of the Glueck's men pointed to dire changes in criminal behavior due to becoming a parent. Because parental activities generally seem to be associated with drastic changes in daily routines, particularly within the first years of parenthood (Osgood and Lee 1993), a more abrupt shift in offending after childbirth can be hypothesized.

The cognitive transformation theory (Giordano et al. 2002) highlights internal individual transformations occurring prior to the transition as determinants of desistance and considers parenthood a hook for change, influencing a more abrupt transformation in an already existing desistance trend. For the cognitive transformation theorists, parenthood is viewed as having the potential to activate change, but this potential only exists if the parents are already motivated to adopt change in their life. In other words, entering a prosocial pathway prior to becoming a parent produces in part a systematic selection into parenthood.

Similar to the cognitive transformation theory, the maturation framework (Maruna 2001) invokes emotional and cognitive transformations as determinants of desistance. Specifically, in the process of becoming adults, individuals move away from criminal behavior because it is considered inconsistent with adult status (Massoglia and Uggen 2010). However, in this view, causal associations between family events and crime are dismissed because individuals do not engage in family roles (e.g., spouse and parent) unless they have undergone the self-transformation (Maruna 2001; Paternoster and Bushway 2009). In other words, parenthood is considered a consequence of desistance rather than a determinant of it.

Although the majority of criminological theories explaining the influence of parenthood on offending highlight a negative association, strain theory (Agnew 1992; 2006) hypothesizes a potential inverse relationship. More specifically, negative relationships and 
situations constitute sources of strain, and individuals respond to this strain through criminal acts (Lilly et al. 2002). Furthermore, parenthood introduces a particular type of strain-economic strain-often associating crime with financial needs (Wakefield and Uggen 2004; Shannon and Abrams 2007). Because financial hardship is common among disadvantaged groups (e.g., high-risk individuals) and children require additional resources, the increased need for necessities (food, housing, and day care) could stimulate involvement in crime, particularly in property crime.

Each of the above-mentioned theories suggests a negative relationship between parenthood and crime with the exception of strain theory, which opens the possibility of an opposite effect. However, the theories differ in defining the moment when the change occurs relative to the time of the transition. Deriving from these theories, we suggest five different ideal-typical average trajectories of criminal behavior related to the transition to parenthood. These hypothetical and stylized trends are illustrated in Fig. 1. First, according to the turning point hypothesis, entrance into parenthood causes a direct change in offending leading toward cessation of crime. This change is gradual but set in motion by the transition (Laub et al. 1998). Second, changes in routine activities define a major shift toward desistance immediately after childbirth. Third, the hook for change hypothesis suggests that the desistance process starts before the transition to parenthood, and we expect additional decline post-birth. Fourth, the maturation hypothesis describes desistance as preceding the transition to parenthood, with no other post-transition changes. Fifth, parental strain hypothesis describes a gradual increase in crime after childbirth. Describing the empirical patterns in the data are thus one basis for discussing to what extent each theory is consistent with the data. Thus, the trajectories in Fig. 1 are theoretical hypothesis to be checked.

Although theories describing the linkage between parenthood and crime do not explicitly address the possibility of gender inequality, distinctive gender-based assumed parental roles might be considered a prerequisite for differences in offending between males and females. The natural predestination of women for pregnancy, birth and breastfeeding offers them a central place in the early life of children. Despite fathers' increased involvement in childcare over the past decades, women remain primary caregivers (Zimmerman et al. 2001). Consequently, mothers will encounter more-drastic changes in daily routines (Cowdery and Knudson-Martin 2005; Kruttschnitt 1996). Given that the father tends to represent the main breadwinner, financial strain might be exacerbated for males, and this strain may be reflected in increases in offending that provide financial gains such as property offenses (Broidy and Agnew 1997). Overall, the theoretical criminal trajectories drawn in Fig. 1 are expected to show a steeper decline for females when following the desistance hypotheses (turning point, routine activities, hook for change, and maturation), whereas the trajectory reflecting parental strain might be characteristic for males.

\section{Empirical Background}

\section{Parenthood and Desistance: A Controversial Relationship}

Qualitative studies are rife with stories evoking parenthood as a catalyst for change for both males (Laub and Sampson 2003; Edin et al. 2004; Shannon and Abrams 2007) and females (Giordano et al. 2002; Edin and Kefalas 2005). Nevertheless, quantitative 


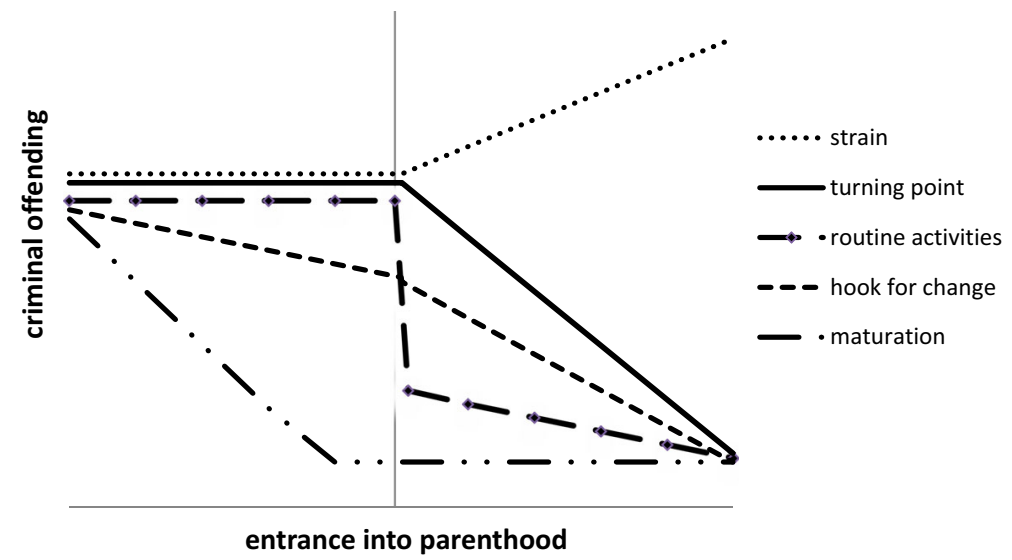

Fig. 1 Theoretical trends of criminal offending

approaches to the interviewed respondents often did not confirm that parenthood actually leads to an embracement of conventional adult roles (Sampson and Laub 1993; Giordano et al. 2011). To date it remains unclear whether quantitative and qualitative studies test different aspects of the parenthood-crime relationship or whether they test similar aspects, but qualitative approaches make unsuitable use of a retrospective view on motivations toward changes in behavior (Kreager et al. 2010).

Several quantitative studies conclude that parenthood reduces offending. In a sample of Finnish recidivist men, Savolainen (2009) found that becoming a father was associated with a $15 \%$ reduction in (re)offending. Findings for high-risk men were confirmed by Zoutewelle-Terovan et al. (2012) in the Netherlands, where fatherhood reduced the rate of offending by $33 \%$. Similarly, results on a convicted sample in the Netherlands (De Goede et al. 2011) showed that first time fatherhood reduces the likelihood of offending by $25 \%$. For females, Kreager et al. (2010) found that both pregnancy and motherhood reduced overall delinquent behavior and stealing. Similarly, Uggen and Kruttschnitt (1998) concluded that mothers were less likely to engage in illegal earning activities.

A different group of studies offered support for the hypothesis that time spent engaged in parental activities is directly linked to changes in offending. In a cross-sectional study, Graham and Bowling (1995) found that females spending most nights at home were three times more likely to desist compared with their counterparts, developing evening activities outside the house. Moreover, for females, desistance was abrupt and directly related to childbearing. The study conducted by Kerr et al. (2011) for males also showed that fathers co-residing with their children the levels of self-reported crime are lower.

Other scholars invoked context effects when describing the parenthood-offending relationship. For males, fatherhood had stronger crime-inhibiting effects when their children were born within a marital relationship (Savolainen 2009), when fathers ensured highquality relationships with their children (Ganem and Agnew 2007), and financial strain and lack of social capital did not affect fathers (Giordano et al. 2011). For females, parenthood inhibited offending when they were involved in daily childrearing (Yule et al. 2014), shared a common household with the biological father, displayed "wantedness" of the pregnancy (Giordano et al. 2011), did not suffer from disadvantageous socioeconomic conditions (Edin and Kefalas 2005) and had high-quality relationships with their children 
(Ganem and Agnew 2007). Such context effects might sustain an ongoing desistance process or serve as an opportunity for change for those already motivated to desist (Giordano et al. 2011).

A different group of studies found no association between parenthood and offending (Wakefield and Uggen 2004; Blokland and Nieuwbeerta 2005). Such results were confirmed when analyzing both males (Sampson and Laub 1993; Graham and Bowling 1995) and females (Giordano et al. 2002; Zoutewelle-Terovan et al. 2012; De Goede et al. 2011).

\section{Parental Strain and Criminogenic Choices}

Scholars such as Ross and Huber (1985) argued that families with children show increased economic strain compared with childless families. A translation of parental strain into criminal activities might occur particularly for disadvantaged individuals experiencing financial hardship (Daly 1998; Giordano et al. 2011), difficult intimate relationships (Graham and Bowling 1995), difficult children (Corman et al. 2011), or limited social support (Giordano et al. 2011). Importantly, high-risk samples are more likely to be exposed to such disadvantages.

Quantitative within-individual analyses showed that parenthood can lead to an increase in offending. When studying individuals with an arrest history, Wakefield and Uggen (2004) concluded that increases in illegal earnings are found only for mothers, regardless of whether the father was present. Another study concluded that parenthood increases illicit drug use within the next year for both males and females, but the effects were stronger for males (Thompson and Petrovic 2009). Between-individual analysis also found that parenthood increases offending. In the UK, Farrington and West (1995) showed that men with a biological child were more likely to be convicted compared with non-fathers. Additionally, men separated from their biological child or conceiving out-of-wedlock had an increased risk of offending. Similar conclusions were extracted when analyzing adolescent fathers (Thornberry et al. 2000). Although it was often true for females that studies could not identify any relationship between parenthood and offending (Kreager et al. 2010; Zoutewelle-Terovan et al. 2012), the study of Giordano et al. (2002) found a positive relationship between parenthood and economic crime.

Other studies found no support for the assumption that parental responsibilities introduce strains leading to increases in crime. Studies connecting parenthood with lower levels of satisfaction and higher levels of stress were predominantly American. However, a Western European study conducted in Finland (Savolainen et al. 2001) showed that custodial parenthood remains unrelated to psychological well-being for females and has a positive effect on males. In the same study, the authors find that fathers are more satisfied with their financial situation compared with non-fathers. A different study conducted by Yule et al. (2014) in Canada showed that, when mothering, female offenders were less likely to earn money illegally.

\section{Timing of Change in Criminal Trajectories}

Life-course research provides ambiguous interpretations of the exact timing of change in offending related to parenthood (before pregnancy, pregnancy related, or birth related). One explanation is that the focus has been placed on modeling pregnancy and/or post-birth causal effects (Kreager et al. 2010) but not specifically on changes in offending in the prepregnancy/birth periods. Because theories (except for strain theory) similarly predict 
decline in offending on average, the timing of change is primarily what differentiates the predictions.

Analyzing changes in offending in the period surrounding the first childbirth, Monsbakken et al. (2013) concluded that for both males and females, the strongest decline in crime occurs pre-childbirth, whereas the transition to parenthood offers the most beneficial long-term effects for men. Because declines in the likelihood to offend occurred long before the pregnancy, the authors' conclusions provide stronger support for the hook for change hypothesis. Moreover, for females, inhibition of crime seems to be related to changes in the daily routines surrounding pregnancy and toddlerhood. Although their study offers a good starting point in describing the timing of change in criminal trajectories, the period (events at a yearly level) might have been somewhat too limited to highlight the mechanisms of change, particularly around pregnancy and childbirth.

\section{Family Formation in the Netherlands and Norway}

After the 1970s, in many Western societies (such as the Netherlands and Norway), familylife trends have become less standardized (Elzinga and Liefbroer 2007), showing increases in unmarried cohabitation, postponement of marriage and parenthood, reductions in teenage pregnancies, and increases in births outside a marital union (Billari and Liefbroer 2010). Although many of those demographic changes have become common, they occurred with different magnitudes in each of the countries analyzed. Whereas the Netherlands follows average trends related to family-formation events in Europe, Norway is considered one of the frontrunners (Sobotka 2008; Kiernan 2004). Overall, cohabitation and marriage among young adult couples in The Netherlands is equally divided, whereas the Nordic countries show the highest incidence of cohabitation, with more than $70 \%$ of couples aged 25-34 registered as cohabiters (Kiernan 2004). Differences between the two countries are also highlighted with respect to non-marital childbearing; whereas the Netherlands has moved from approximately $2 \%$ in 1970 to approximately $25 \%$ in the 2000s, Norway has moved from approximately $8 \%$ in 1970 to approximately $50 \%$ in the 2000s (Kiernan 2004; Perelli-Harris et al. 2012). Concerning the average age of mother's first childbirth, the two countries followed relatively similar developments. In the Netherlands, the average age of a female's first birth was 24.3 in 1970 and 29.4 in 2010; in Norway, females entered parenthood on average at age 23.2 in 1970 and at age 28.2 in $2010 .{ }^{1}$

Although both are modern European societies, the Netherlands and Norway provide different parental benefits within the social system (Thevenon 2011), and these differences could shape distinct criminal trajectories for each country. International comparisons show that the Netherlands has one of the least generous pregnancy and birth schemes (Gauthier 2014). For example, mothers in the Netherlands receive 16 weeks of paid maternal leave, whereas in Norway, mothers are entitled to fully paid leave of 46 weeks, with the option of extending the period with proportionally less pay each month. The differences for fathers are also considerable. In the Netherlands, a man may take 2 days of paternity leave when a child is born, whereas a father in Norway benefits from a total parental leave quota of at least 12 weeks (fully paid). Moreover, unpaid leave for fathers in the Netherlands can be taken for 26 weeks, whereas fathers in Norway may request up to 1 year of unpaid leave. Considerable differences between the two social systems are also observed in the day care

1 Sources: Statistics Netherlands-www.cbs.nl; Statistics Norway-www.ssb.no. 
facilities for parents. Day care in Norway is heavily subsidized and guaranteed by the government (starting from age 1 of the child), whereas costs for parents in the Netherlands are relatively high. The more parental-friendly social policies in Norway (such as longer parental leave, childcare at highly subsidized rates, and workplace flexibility) could reduce parental strain and thus lead to lower offending rates after childbirth. Conversely, the presence of good childcare facilities might diminish or negate the influence of parenthood on offending.

\section{Method}

\section{Sample}

For this study, two contemporary at-risk samples from the Netherlands and Norway were considered. We started with data from a longitudinal study performed in the Netherlands that contained individuals institutionalized during adolescence in a juvenile treatment center. The 540 Dutch respondents (270 males, 270 females) were born between 1969 and 1977 and were treated in a residential care setting for behavioral or familial problems, often including delinquency. With an aim to analyze behavioral changes before and after the birth of the first child, we selected from the 540 individuals only those who became parents $^{2}$ (100 males and 191 females). Although there is no directly comparable setting in Norway for the Dutch study, the system of registry data containing the total Norwegian population (Lyngstad and Skardhamar 2011) allows great flexibility to select various samples based on specified criteria. To specify these criteria, we focused on two aspects: (a) obtaining similar samples based on youth factors (criminal involvement and family background) and (b) obtaining similar samples based on characteristics related to entrance into parenthood (age and marital status when entering parenthood and criminal involvement).

The construction of the Norwegian sample proceeded as follows. First, we retained only individuals from the total Norwegian population who became parents up until age 33 (as was the case in the Dutch sample) and were born between 1970 and 1990. Second, for both Dutch and Norwegian parents, we constructed a set of variables to be used further in the matching procedure: parents divorced (dichotomous variable showing whether individuals experienced divorce of the biological parents in youth ${ }^{3}$ ); youth offending (dichotomous variable recording whether the individuals committed an offense before age 16); offender 16 to 1 st child (dichotomous variable showing whether an individual committed an offense between age 16 and childbirth); age of entering parenthood (categorical variable recording the age range in which individuals entered parenthood using 3-year age ranges ${ }^{4}$; the variable contains six categories, with the first category including ages 16-18, and the last

\footnotetext{
2 A question that arises with registered data is whether entrance into parenthood is properly addressed, given that individuals (particularly males) might have become parents earlier without an official parental registration. We can address the issue on a subsample of Dutch respondents $(n=139)$, who have been recently interviewed. With the exception of five males and three females, there was concordance between registered and self-reported information on all parenthood data. Thus, we do not consider unregistered parenthood a reason for concern.

3 This variable was measured at institutionalization in adolescence for the Dutch respondents and at age 18 for the Norwegian respondents.

4 Although initially we focused on an exact age match, the procedure failed to identify a matching sample for the analysis given the low number of inhabitants in Norway (approximately 5 million individuals) and
} 
category ages 31-33); married at childbirth (binary variable showing whether individuals were married when the first child was born); and gender (binary variable showing whether a respondent is male or female). In the third step, we focused on the Dutch sample and constructed frequency distributions of all possible combinations of the previously defined variables. For example, this six-way cross tabulation showed for one of its cases that, from the total of 191 women, 4 of them had their first child between ages 25 and 27, did not experience parental divorce in youth, did not offend in youth or at any moment before entering parenthood and were not married when the first child was born. In the fourth step, we randomly selected the same number of Norwegian persons, replicating exactly the contingency table of the Dutch sample on the specified criteria. Following the previous example, the Norwegian sample now also contains 4 females who became parents between ages 25 and 27, did not experience parental divorce in youth, did not offend in youth or before entering parenthood and were unmarried when the first child was born.

The implemented matching procedure implemented ensured the availability of two samples (Dutch and Norwegian) resembling the exact combinations of the specified characteristics. After processing additional exclusion criteria (availability of post-birth information and controlling for death and emigration), the at-risk groups for this study included 93 males and 186 females for the Dutch sample (the high-risk sample) and 100 males and 189 females for the Norwegian sample (the elevated-risk sample). In both samples, individual-level information was used for a period of a maximum of 121 months, with a median observation period of 106 months for the Dutch data and 121 months for the Norwegian data.

\section{Data and Measures}

\section{Data Sources}

For the sample in the Netherlands, information on parenthood, marital status and other demographic variables was obtained from the Municipal Population Register, a centralized electronic registration system containing data on all registered inhabitants of the Netherlands. Information on criminal offending was obtained from Judicial Documentation abstracts of the Ministry of Justice (comparable with "rap sheets"). These files contain information on all cases registered by the police at the Public Prosecutor's Office, offenses committed and the corresponding verdicts. Offenses were recorded starting at age 12, the minimum age of criminal responsibility in the Netherlands. Furthermore, offenses followed by acquittals or so-called technical dismissals were eliminated from the analysis. Information on parental divorce was obtained from personal files completed during institutionalization in the juvenile treatment center (see van der Geest et al. 2009).

For the Norwegian sample, we extracted information from the administrative records at Statistics Norway, in which data from different databases can be linked at the individual level on personal identification numbers. For this study, the population registers provided information on family background, parental and marital status, and other demographic data. The criminal statistics register system (linked with police records) provided information on all solved cases associated with criminal offenses. For the current analysis, we used only cases for which a legal decision against the perpetrator was taken because for a

Footnote 4 continued

the conditioning on a relatively complex set of inclusion criteria. For the final selection, we used 3-year age ranges. 
considerable number of committed offenses, the prosecution is dropped although the perpetrator was found (e.g., mental health problems or case transferred for mediation). Furthermore, the solved cases included complete information on each offense and the exact date when the offense was committed. Finally, we registered offenses followed by criminal charges (and not convictions) starting with age 10. This approach offered the possibility to extend the observation period concerning criminal involvement because convictions would have been recorded only starting with age 15 (the minimum age of criminal responsibility in Norway).

\section{Variables}

Grouping Variables To ensure the grouping of all variables around entrance into parenthood, a time-varying time variable was constructed. The variable contained for each individual a maximum of 121 months (time points) around the birth of the first child, with values ranging from -60 to +60 (negative values for pre-childbirth months, positive values for post-childbirth months, and 0 for the month of childbirth). Additionally, we constructed the binary variable period to separate observations into two periods: prechildbirth months (value of 0 ) and post-childbirth months-including the month of childbirth (value of 1).

Dependent Variables The overall criminal offending of the individuals was recorded as a binary time-varying indicator distributed around entrance into parenthood to fit the format of the time variable. The variable takes a value of 1 in each month a person committed at least one offense ( 0 otherwise). For the second step of the analysis, focusing on changes in offending possibly associated with economic needs, we constructed a dichotomous timevarying variable reflecting respondents' involvement in property offending for each month under observation $(1=$ committing at least one property offense). By using dichotomous dependent variables, we classify individuals into offenders and non-offenders, thus focusing on the analysis of cessation of crime rather than reduction/increase in crime.

Covariates To isolate the effects of parenthood from aging effects, we constructed a time-varying age variable recording the exact age of the individual (in years) at the beginning of each observed month. Because previous literature suggested that the relationship between parenthood and offending is moderated by marriage, we constructed a time-varying dichotomous variable showing the marital status of the person in each specific month under observation $(1=$ married). Furthermore, to account for youth offending, a time-invariant binary variable was constructed $(1=$ committing at least one offense before age 16). Finally, the variable additional children was constructed as a dichotomous time-varying variable controlling for the presence of additional children born within the observation period $(1=$ one or more other children).

\section{Analytic Strategy}

The theoretical discussion presented above derives empirical implications from each causal theory related to the timing of change. Thus, our analytical strategy is to investigate to what extent empirical patterns correspond to the hypothesized patterns. Our approach does not 
provide direct causal estimates, ${ }^{5}$ but we qualify the plausibility of the theoretical causal claims based on the trends observed.

The chronological occurrence of events was accounted for by variables grouping information around the birth of the first child in a person-month file. For the analysis, we recorded information starting with the 60th month before the birth of the first child through the 60th month after childbirth. Naturally, monthly measures result in lower absolute levels of offending than if using yearly measures, but it allows for more detailed analyses of the patterns. The pattern of change over time in criminal trajectories related to the entrance into parenthood was modeled using generalized additive models (GAMs), also known as nonparametric smoothing splines. GAMs are extensions of the more familiar generalized linear models, with the specification that the linear predictor represents a sum of smooth functions of determined covariates (Wood 2006). By specifying models in terms of smooth functions rather than parametric relationships, GAMs offer high flexibility in the contour of the trends without pre-imposing an overall specific shape (e.g., linear or curvilinear).

A general structure of a smoothing spline containing a smooth function of a single covariate is defined as follows:

$$
y_{i}=f\left(z_{i}\right)+\varepsilon_{i}
$$

where $y$ represents the outcome variable, $f$ is a smoothing function of the covariate $z$, and $\varepsilon$ is the error term (Wood 2003). Because the use of smoothing splines is less common in criminology, we provide a more detailed explanation of the technique. The principles behind this method are perhaps best understood when using the most basic specification of the smooth function, which is to define it as a cubic spline. Wood (2006) offers a visual representation of a cubic spline, which is replicated in Fig. 2. For this spline, $f$ is separated into segments of cubic polynomials joined to become continuous up to the second derivatives. The points at which the sections of the cubic polynomial are united are called knots and are spread evenly through the covariate values.

A limitation of the cubic spline (and of polynomial splines in general) is that it makes arbitrary choices about the smooth basis, knot locations, and the number of knots (see also Skardhamar and Savolainen 2014). With the aim of providing regression splines following as closely as possible the natural development of the data, we chose to fit thin plate regression splines (TPRS). The TPRS as defined by Wood $(2003,2006)$ have the advantage of balancing between under-smoothing and over-smoothing and do not force one to make choices about basis functions or knots because the parameters to be estimated result directly from the data. ${ }^{6}$

The general structure of the GAM containing a smooth function of a single covariate (in our case time) defines the expected outcome for person $i$ at time point $t$ as the following:

$$
g\left(\mu_{i t}\right)=\beta_{0}+f\left(\text { time }_{i t}\right)+X_{i t} \theta
$$

where $g$ is a specific link-function, $\beta_{0}$ represents the overall intercept, $f$ is a smoothing function of the time covariate, and $X_{i t}$ contains the vector of parametric terms (explanatory

\footnotetext{
5 Estimating counterfactual causal effects requires a quasi-experimental situation that is difficult to justify for family-related transitions. We agree with other scholars who have argued that finding credible instrument variables is unrealistic (Sampson et al. 2006), and that techniques such as fixed effects and propensity score methods are insufficient for causal interpretation (Bjerk 2009; Skardhamar et al. 2015). Conversely, insights about causality can also be achieved without causal estimates (Berk et al. 2014).

6 As detailed explanations of the TPRS go beyond the purpose of this study, we recommend interested readers to consult Wood $(2003,2006)$.
} 


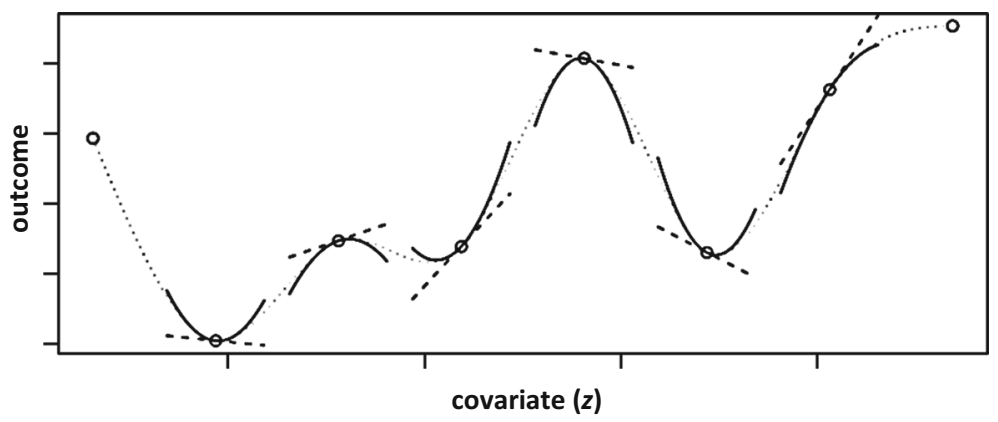

Fig. 2 Example of a cubic spline presented by Wood (2006, p. 124)

variables) with the corresponding estimated coefficients $\theta$. However, because we wanted to estimate the amount of change in offending at the transition point (birth of the first child), the use of a single smoothing term (Eq. 2) would have been unable to capture any shifts in offending occurring at the month of childbirth. We addressed this issue by introducing a discontinuity in the pattern and fitting the spline function separately for the pre-birth and post-birth periods as follows:

$$
g\left(\mu_{i t}\right)=\beta_{0}+k_{i t} \beta_{1}+f_{1}\left(\text { time }_{i t}\right)+f_{2}\left(\text { time }_{i t}\right) \times k_{i t}+X_{i t} \theta
$$

In this third equation, the $\beta_{1}$ coefficient captures the difference in offending at the moment of birth, whereas $k$ represents the period variable separating pre-birth and postbirth periods.

Following the binomial distribution of the dependent variable (offending), we specified models as logistic regressions, controlling for a set of explanatory variables (youth offending, marital status, and additional children). In addition, to capture the curvilinear relationship between aging and offending, we controlled for linear and quadratic age variables. Given our focus on gender and cross-national differences, separate models were estimated for each gender within each country. Note that results of the smoothing splines have a less straightforward interpretation because the non-parametric estimate does not provide conventional regression parameters (because multiple coefficients are estimated for each segment of data). For this reason, the results are reported as predicted probabilities at the sample mean for the covariates. Furthermore, because the GAM model is an extension of the ordinary regression model to include nonparametric smoothing splines, the parametric terms are interpreted in the usual way (in our case as in logistic regression). Thus, given the centering of the timing variable, the coefficients are interpreted as conditional log odds in the month of childbirth. All analyses were performed by use of R Core Team and the mgcv package for GAMs.

\section{Results}

\section{Descriptive Statistics}

\section{Parenthood}

Both similarities and differences are observed between countries and across genders. On average, at-risk males had their first child at age 27 in the Netherlands and age 26 in 
Norway. In both countries, at-risk females gave birth to their first child at age 21 on average. Furthermore, both Dutch and Norwegian females entered parenthood earlier compared with the males: before 20 years of age, $48.9 \%$ of the Dutch females and $43.9 \%$ of the Norwegian females became mothers (compared with $6.5 \%$ of the Dutch males and $7.0 \%$ of the Norwegian males). Within the 5 years observed after childbirth, $37.6 \%$ of the Dutch males and $42.5 \%$ of the Dutch females became parents again, whereas in Norway, $33.0 \%$ of the males and $40.1 \%$ of the females had additional children. Note that none of the at-risk individuals in our samples had a child before age 16.

To understand better the characteristics of the at-risk groups in relation to population patterns, we compared our at-risk persons with comparison groups extracted from the general population. The comparisons group for the Netherlands contained individuals in the total population matched one-by-one with the initial 540 risk individuals based on date of birth, gender (and name initials in case of multiple matches). Furthermore, only individuals becoming parents were retained in the control groups. For Norway, conditioned on individuals entering parenthood through age 33, an exact match on gender and date of birth were performed (followed by a random selection of individuals in the few cases in which multiple matches were retained after the first two selection criteria). Figure $3 a, b$ offers a country-specific overview of the entrance into parenthood patterns for both at-risk and control groups. With no outstanding country differences observed for males, the graphs show that both at-risk and control males develop relatively similar trends (with at-risk males entering parenthood slightly earlier). For females, although the trends for at-risk groups are almost identical across countries, visible differences are observed when comparing them to their control groups. In the Netherlands, approximately $62.4 \%$ of the highrisk females had their first child before age 21 , compared with only $4.6 \%$ in the control group (who reached the same percentage only around age 29). In Norway, the differences between elevated-risk and control females are smaller; by age 21, approximately $60.3 \%$ of the elevated-risk females gave birth to their first child compared with $33.3 \%$ in the control group (the control group reached the same percentage around age 24).

A The Netherlands

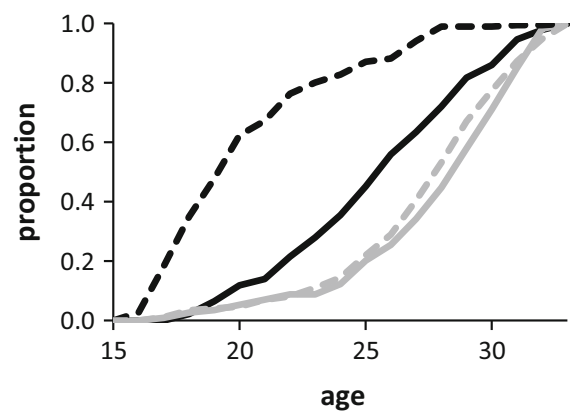

B Norway

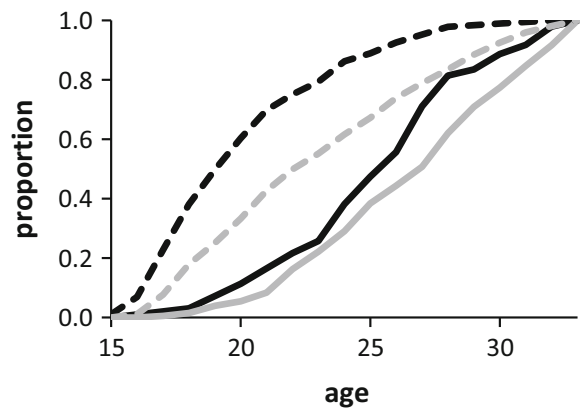

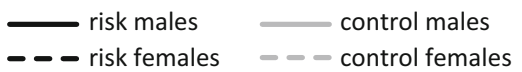

Fig. 3 Cumulative distribution of the age of entering parenthood 


\section{Criminal Offending}

A considerable number of individuals in our at-risk samples engaged in criminal behavior at early ages. Due to the matching procedure, engagement in criminal behavior in youth was similar for the Netherlands and Norway $(69.0 \%$ of the at-risk males and $42.9 \%$ of the at-risk females committed at least one offense before age 16).

For a better understanding of the development of criminal behavior of our at-risk individuals, we provided age-crime curves for the complete criminal follow-up and compared them with the corresponding crime trends of the control groups extracted from the general population. Figure $4 a$, b presents the prevalence of offending at every specific age observed. For Dutch males, high discrepancies in offending are recorded between high-risk and control groups. Although for the controls, the highest value registered was $5.7 \%$, for the high-risk group $12.9 \%$ was the lowest value recorded (with peaks observed at ages 15-16, when $52.7 \%$ of the males offend at least once). Dutch high-risk females show lower offending proportions compared with the males, but their criminal conduct remains elevated compared with the female control group. Whereas for the Dutch control females the trend is almost level at 0 , most high-risk females commit offenses in youth (highest peak observed at age 14, when $22.6 \%$ of the females offend at least once). Although overall the Norwegian at-risk groups show lower proportions of offending across time, the general trends of the elevated-risk and control groups are similar to those described above for the Dutch groups. Elevated-risk Norwegian males record the highest prevalence at age 15, when $35.2 \%$ of the individuals commit at least one offense, whereas the values for control males do not exceed $4.6 \%$ for any of the observed ages. Elevated-risk Norwegian females register their peak in offending at age 17 , when $12.9 \%$ of the females commit a criminogenic act at least once, whereas for the control females, proportions are almost leveled-off at 0 (peak registered at age 30, when only $1.2 \%$ of them were involved in crime). For all at-risk groups under observation, a general decreasing trend is observed during aging.

\section{Other Descriptives}

Given the matching procedure, the groups in both the Netherlands and Norway are very similar with respect to their marital status at birth (approximately three in 10 males and one
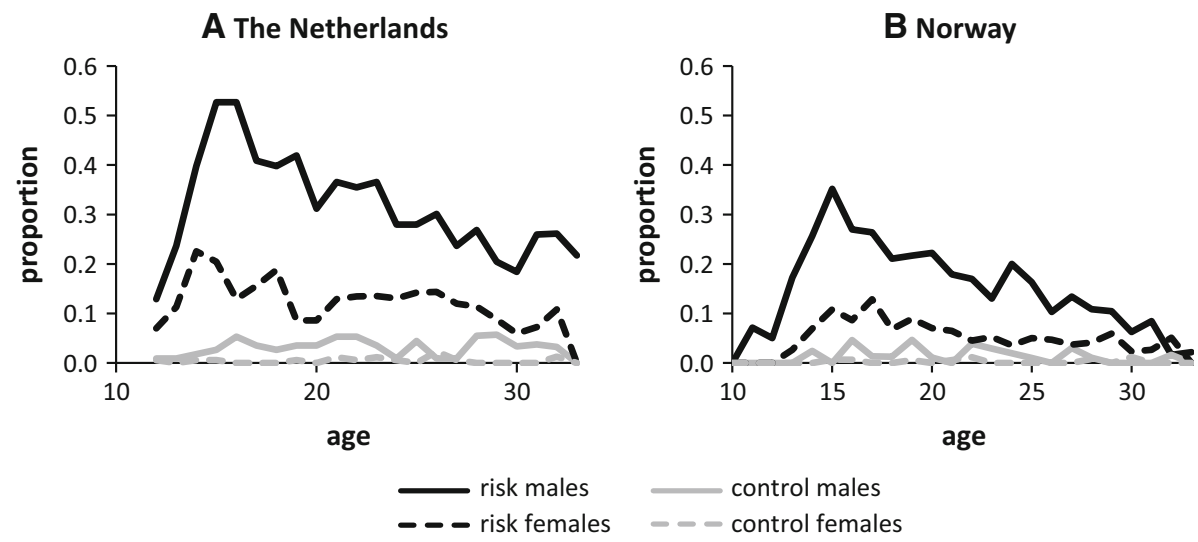

Fig. 4 Proportions of offenders by age 
in 10 females were married when the first child was born). Nevertheless, some differences appear when analyzing marital status during the entire 10-year observation period for the at-risk respondents; in the Netherlands $38.6 \%$ of the males and $20.4 \%$ of the females were married at least once, whereas in Norway, $50.0 \%$ of the males and $23.8 \%$ of the females were married.

The matching procedure also ensured very similar groups with respect to parental divorce in the family of origin. In both the Dutch and Norwegian at-risk samples, approximately $57.0 \%$ of the males and $67.0 \%$ of the females experienced parental divorce at early ages.

\section{Changes in Offending Trends Around the Entrance into Parenthood}

\section{Models for Overall Offending}

Sample in the Netherlands Figure 5a, b presents the results of the smoothing splines (and corresponding confidence intervals) for the high-risk males and females in the Netherlands. For males, there is a slight gradual decline in the monthly probabilities to offend prior to the month of childbirth from approximately 5-4\%. At childbirth, a shift in offending of approximately $1 \%$ point is observed, and this month has the lowest probabilities to offend. Post-birth, we found a rebound effect, in which the probabilities of offending increase and reach levels higher than before becoming a parent. The highest probabilities are recoded at the end of the tracking period. For the models fitted, overall approximate significance tests of smooth terms are provided. These tests are shown in Table 1. However, as Clark (2012) notes, the tests should be interpreted with caution. For males, the overall test shows a nonsignificant decline in offending probabilities pre-childbirth, whereas we found a significant post-childbirth increase in offending (Table 1).

For high-risk females, although the monthly probabilities to offend remain low (approximately $2 \%$ ) during the entire observation period (Fig. 5b), a specific pattern around childbirth is notable. At the beginning of the pre-birth period (for approximately 3-4 years), the probabilities to offend show a flat pattern (also see confidence intervals) followed by a decline approximately 1.5 years before birth. The pregnancy period is

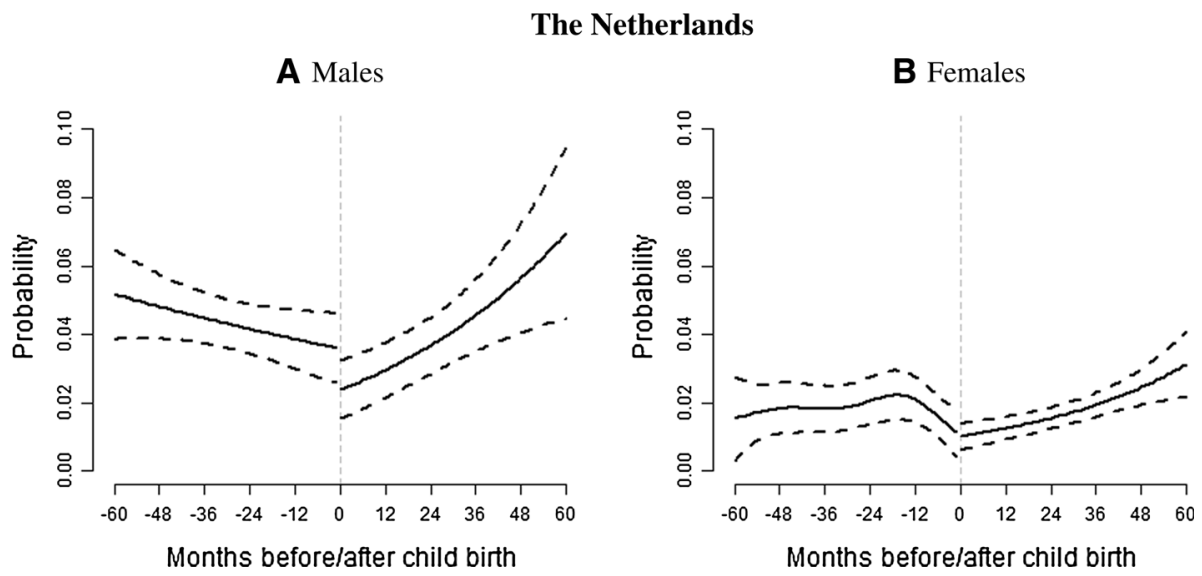

Fig. 5 Smoothed splines of criminal offending - The Netherlands 
Table 1 Overall approximate significance of smooth terms

\begin{tabular}{|c|c|c|c|c|c|c|c|c|}
\hline \multirow[t]{3}{*}{ Smooth terms } & \multicolumn{4}{|c|}{ The Netherlands } & \multicolumn{4}{|c|}{ Norway } \\
\hline & \multicolumn{2}{|l|}{ Males } & \multicolumn{2}{|c|}{ Females } & \multicolumn{2}{|l|}{ Males } & \multicolumn{2}{|c|}{ Females } \\
\hline & edf & $p$ value & edf & $p$ value & edf & $p$ value & edf & $p$ value \\
\hline \multicolumn{9}{|c|}{ Overall offending } \\
\hline Pre-birth & 1.007 & .103 & 3.322 & .605 & 3.498 & .027 & 4.392 & .002 \\
\hline Post-birth & 1.003 & .000 & 1.133 & .000 & 1.595 & .063 & 1.351 & .027 \\
\hline \multicolumn{9}{|c|}{ Property offending } \\
\hline Pre-birth & 1.797 & .134 & 1.018 & .847 & 2.098 & .055 & 3.751 & .056 \\
\hline Post-birth & 1.001 & .101 & 1.042 & .014 & 1.001 & .005 & 1.769 & .293 \\
\hline
\end{tabular}

$e d f$ effective degrees of freedom

Table 2 Coefficients for the parametric predictors in GAMs (overall offending)

\begin{tabular}{|c|c|c|c|c|}
\hline \multirow[t]{2}{*}{ Variables } & \multicolumn{2}{|c|}{ The Netherlands } & \multicolumn{2}{|l|}{ Norway } \\
\hline & Males & Females & Males & Females \\
\hline Intercept & $-8.426 * * *$ & $-10.581 * * *$ & $-5.534 * *$ & $-13.551 * * *$ \\
\hline Age & $0.429 * *$ & $0.407 *$ & $0.227^{*}$ & $0.375^{* *}$ \\
\hline $\operatorname{Age}^{2}$ & $-0.009 * *$ & -0.009 & $-0.008 * *$ & $-0.009 * *$ \\
\hline Period (before/after birth) & $-0.507^{*}$ & 1.156 & 0.394 & 2.891 \\
\hline Youth offending & $0.645 * * *$ & $0.503 * * *$ & $0.533^{* * *}$ & $1.739 * * *$ \\
\hline Marital status & $-0.586^{* *}$ & -0.457 & $-0.401^{*}$ & $0.663 * *$ \\
\hline Additional children & $-0.597 *$ & $-0.651 * *$ & $0.255^{*}$ & 0.021 \\
\hline Adjusted $\mathrm{R}^{2}$ & 0.009 & 0.003 & 0.016 & 0.015 \\
\hline
\end{tabular}

$* * * p<.001 ; * * p<.01 ; * p<.05$

associated with the lowest probabilities to offend for females, and no noticeable shift is observed at birth. The post-birth period is characterized by increases in the probabilities to offend and, similar to the males, this increase was statistically significant (Table 1).

In addition, our models for the Dutch individuals included a set of observable characteristics. The estimated parametric terms can be found in Table 2. The coefficient for period shows a significant shift at time $=0$ for males and a non-significant one for females. In other words, for males, the likelihood to become involved in crime diminishes by $40 \%^{7}$ at childbirth. Furthermore, youth offending remains a significant predictor of later offending for both genders. In line with results from previous studies, marriage is significantly associated with declines in the probabilities to offend for males, but no significant effect is registered for females. Finally, having additional children significantly reduces the likelihood to offend for both males and females.

Sample in Norway For the Norwegian sample, Fig. 6a, b presents the monthly probability trends for the elevated-risk respondents. The monthly levels of offending are similar to the ones in the Dutch sample (approximately $4 \%$ for males and $2 \%$ for females). For males, most of the pre-pregnancy period is characterized by increases in the probabilities to

$\overline{7}$ Percentage calculated as $((\exp \beta-1) \times 100)$, where $\beta$ represents the estimated coefficient. 
offend, with the steepest increase in the first 1.5 years of the observation period. A slight decline continues during the pregnancy, and no substantive shift is observed at childbirth. A rebound effect occurs post-birth, and a gradually increasing path of offending is observed for the remaining months. At the end of the observation period, males register the highest probabilities to offend, with a point estimate close to $6 \%$. For the Norwegian females, the trend is very similar to the Dutch one-a relatively flat line in the prechildbirth period with a small dune approximately 2 years before birth (although with overlapping confidence intervals), followed by a more steep decline during pregnancy. Although there is no actual shift in the probability of offending at childbirth, the postchildbirth period provides slight increases in the probabilities of offending. An overall test of the smoothing terms shows that the significant changes for males occur pre-birth, whereas statistical significance for females is recorded both pre-birth and post-birth (Table 1). However, the statistical significance post-birth for females should be interpreted with caution.

The estimated coefficients of the covariates introduced in our GAMs for the Norwegian respondents are presented in Table 2. For both Norwegian males and females, no significant shift in the offending trend was recorded in the month of childbirth. Youth delinquency was significantly associated with higher likelihoods of offending in adulthood for both Norwegian males and females. Furthermore, marriage for both genders was associated with significant changes in the likelihood of offending. Nevertheless, the direction of the effects is opposite; males show lower probabilities to offend if married, whereas females show higher probabilities to offend when married. Finally, having additional children significantly increases the likelihood of offending for males.

Note that an extended model specification for this study included additional control for incarceration periods. After concluding that incarceration does not represent a bias element in the relationship investigated, we allowed for a clear comparability of the models and presented results without controlling for incarceration. ${ }^{8}$

\section{Models for Property Offending}

Although it was not a specific goal of the current study to analyze the timing of change in criminal offending for specific types of offenses, results from the main analysis recording overall offending showed increases in the probabilities to offend after entrance into parenthood. Because strain theory places an additional focus on increases in economic crime related to parental strain, we performed additional analyses for property offenses as an outcome.

Sample in the Netherlands For the Dutch high-risk males (Fig. 7a), the trend in property crime shows a systematic decline of $1 \%$ point prior to entrance into parenthood. However, this decline remains non-significant (Table 1). With no significant shift in property offending at childbirth, the probabilities to offend almost stabilize post-birth. For females (Fig. 7b), the pre-birth period is characterized by a flat, low-leveled trend followed by

\footnotetext{
${ }^{8}$ For all males (Dutch and Norwegian), incarceration had no influence on their criminal trends. For the Norwegian females, we found a very small number of incarcerations spells, and models including incarceration failed to converge, whereas incarceration for the Dutch females only slightly reduced the peak in offending probabilities observed approximately 1.5 years before birth. However, it remained in the boundaries of the confidence interval and provided a minimum improvement to overall explained deviance. This result is not necessarily surprising, because both countries provide non-punitive penal policies with low incarceration rates and short incarceration periods.
} 


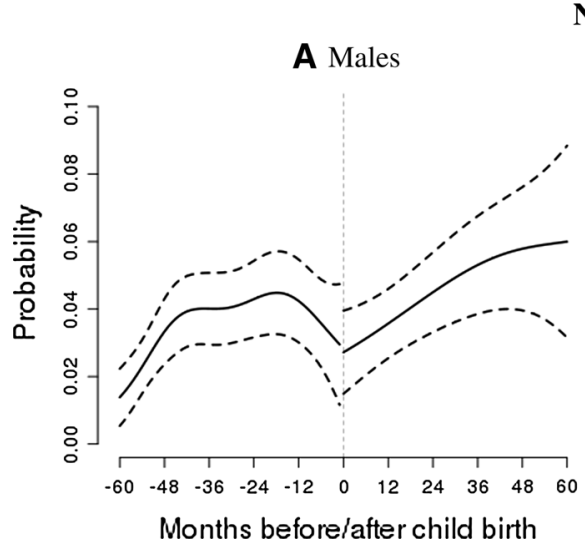

\section{Norway}

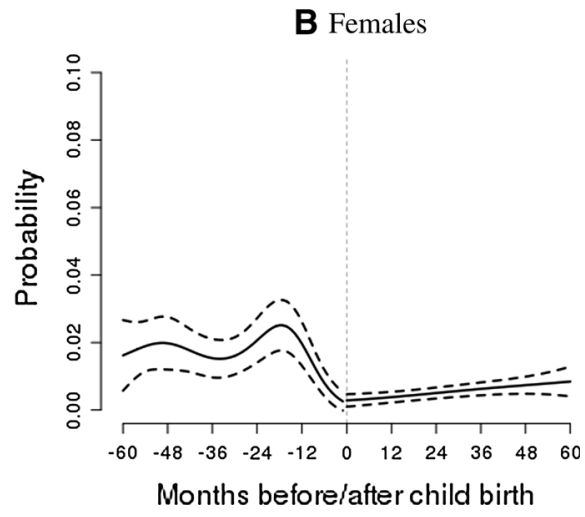

Fig. 6 Smoothed splines of criminal offending-Norway

\section{The Netherlands}
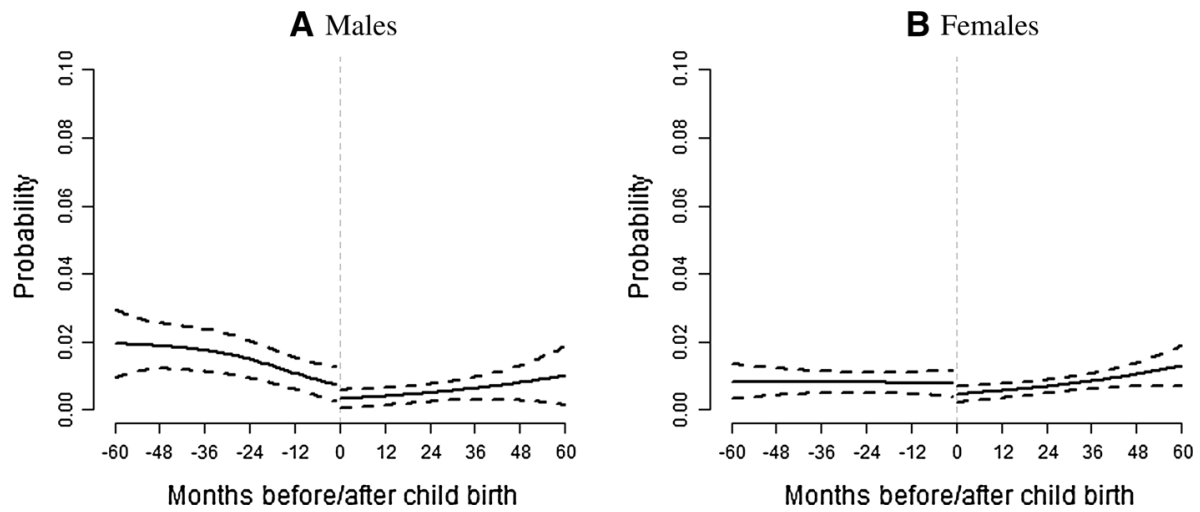

Fig. 7 Smoothed splines of property offending-The Netherlands

slight increases post-birth. Although the post-birth increase reached the significance level (Table 1), the test should be considered marginal. Nevertheless, at the end of the observation period, females register the highest probabilities to commit property offenses (approximately $1 \%$ higher compared with the month of birth). The estimated coefficients of all covariates introduced in our regression models for property offending are listed in Table 3.

Sample in Norway For the Norwegian elevated-risk sample, the trends are slightly different. Males (Fig. 8a) show a slight increase in the probabilities to commit property offenses until approximately 2 years pre-childbirth, followed by a relatively flat trend up to childbirth. The post-childbirth period stands out because the probabilities of committing property offenses increase steeply, and, at the end of the observation, they are approximately $3 \%$ points higher compared with pre-birth months. The statistical test for the post- 
Table 3 Coefficients for the parametric predictors in GAMs (property offending)

\begin{tabular}{|c|c|c|c|c|}
\hline \multirow[t]{2}{*}{ Variables } & \multicolumn{2}{|c|}{ The Netherlands } & \multicolumn{2}{|l|}{ Norway } \\
\hline & Males & Females & Males & Females \\
\hline Intercept & $-9.579 * *$ & $-7.801 *$ & $-12.945^{* * *}$ & $-11.930 * * *$ \\
\hline Age & 0.354 & 0.260 & $0.877 * * *$ & 0.178 \\
\hline $\mathrm{Age}^{2}$ & -0.007 & -0.006 & $-0.023^{* * *}$ & -0.005 \\
\hline Period (before/after birth) & -0.851 & -0.422 & 0.305 & 1.354 \\
\hline Youth offending & $0.994 * * *$ & $0.807 * * *$ & 0.326 & $2.308 * * *$ \\
\hline Marital status & -0.325 & -0.794 & 0.301 & 1.189 *** \\
\hline Additional children & -0.889 & -0.541 & -0.025 & 0.131 \\
\hline Adjusted $\mathrm{R}^{2}$ & 0.007 & 0.002 & 0.011 & 0.012 \\
\hline
\end{tabular}

$* * * p<.001 ; * * p<.01 ; * p<.05$

childbirth smoothing function confirms this increase because it reaches significance (Table 1). For the Norwegian females (Fig. 8b) property offending probabilities remain relatively low (approximately $1 \%$ ) during the entire observation period (with postchildbirth probabilities never reaching pre-pregnancy levels). The estimated coefficients of all covariates included in the property offending models are presented in Table 3.

Overall, the post-transition probabilities show an almost indistinguishable increasing trend in property offending, with the exception of Norwegian males showing a systematic post-birth increase.

A final observation is related to the magnitude of the observed changes. Compared to previous studies, the base rate of offending in this observation window might appear low (under $7 \%$ for all groups investigated). Thus, the changes are of small magnitude in absolute terms, and cannot be expected to be major drivers of the aggregate patterns of desistance. On the other hand, these analyses are based on monthly measures to capture the timing of changes in more detail, and the crime rates would have been larger in absolute terms if we had used yearly measures. Thus, the level of offending is not quite trivial either. However, the substantive meaning of these results is related to when changes occur rather than the size of any causal effects. The results presented above might suggest that

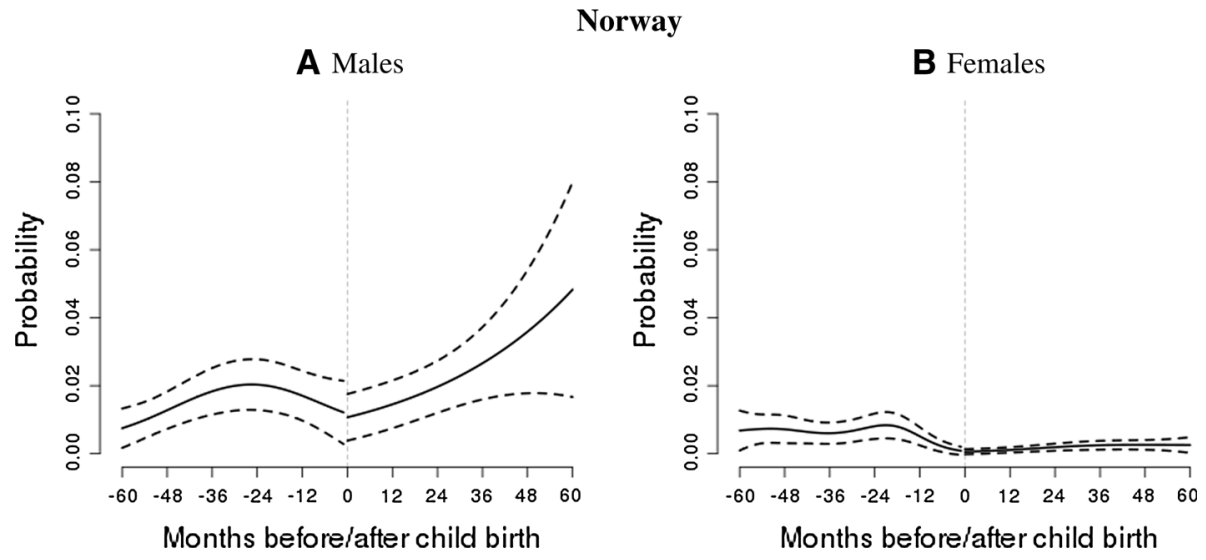

Fig. 8 Smoothed splines of property offending-Norway 
parenthood is not a major explanatory factor of desistance since the absolute changes are low, and so is the initial level of offending. On the other hand, the core theoretical point is related to tendencies in the timing of change rather than magnitude of effects, of which we turn to in the next section.

\section{Discussion}

According to the age-graded theory of social control (Sampson and Laub 1993; Laub and Sampson 2003), becoming a parent holds the potential to be a turning point in one's criminal involvement, promoting desistance. The causal nature of the relationship described by Sampson and Laub implies that any decrease in offending should occur after the transition to parenthood. Following the arguments of routine activity theorists (Cohen and Felson 1979; Horney et al. 1995; Warr 1998), entrance into parenthood is expected to diminish time spent with (deviant) peers and lead individuals toward a more conforming lifestyle. However, changes in routine activities may occur immediately at birth for men but at the time of pregnancy for women. A different perspective on change is given by the theory of cognitive transformation, suggesting that parenthood may trigger changes in offending but only if preceded by an internalized commitment to change leading to desistance (Giordano et al. 2002). Hence, actual changes in offending should be visible both before and after the transition. The related perspective on maturation (Maruna 2001) implies that desistance occurs well ahead of the transition, and the transition itself remains unrelated to crime. When contrasting these theories, we conclude that an important element that sets theoretical predictions apart is the timing of change.

The main purpose of this study was to evaluate to what extent parenthood affects criminal behavior consistent with existing theoretical assumptions. If parenthood affects on offending, changes in criminal paths must be observed after childbirth. Any changes in offending occurring before the transition to parenthood question the causal nature of the parenthood-crime relationship. To investigate the timing of change in criminal trajectories around entrance into parenthood, we analyzed a sample of at-risk individuals. Gender differences in the timing of change were also studied. Additionally, to understand whether effects and timing of change remain the same regardless of national contexts, we conducted analyses in two different social settings: the Netherlands and Norway.

Results of the analyses showed that, for all at-risk individuals in our study (men or women, Dutch or Norwegian), criminal involvement declined prior to becoming a parent and even before pregnancy. These results are consistent with the findings of Monsbakken et al. (2013) based on a general population sample in Norway. Unfortunately, we could not identify other studies focusing on the timing of change around entrance into parenthood in other social contexts or using different samples and methodologies. Additionally, our results showed that respondents were least likely to offend in the month of childbirth. However, after the birth of the first child, we registered increases in criminal involvement during the entire remaining period. The post-transition trend showing increases in criminal involvement is intriguing because many existing studies described an opposite relationship between parenthood and crime (see Savolainen 2009; Kreager et al. 2010; Uggen and Kruttschnitt 1998, Kerr et al. 2011). However, desistance may occur only in certain conditions such as sharing a common household with the other parent, having the custody of the child, or having a high quality parent-child relationship (Farrington and West 1995; Ganem and Agnew 2007; Giordano et al. 2011). Because in this at-risk groups we cannot 
be sure that such conditions were met, we can speculate that the increase in crime is explained by the lack of a 'desirable' parental environment.

From a theoretical perspective, declines in criminal offending occurring before the transition to parenthood tend to align with assumptions of the cognitive transformation (Giordano et al. 2002) and maturation (Maruna 2001) frameworks because the early changes might reflect ongoing processes and a readiness for change. However, the posttransition pattern contradicts the expectancies of both mentioned theories. Becoming a parent does not represent a hook-for-change in crime reduction, as the cognitive transformation theory assumes. Additionally, because the personal commitment to change observed pre-transition was not sufficiently strong to resist negative after-transition transformations, nor do we find sufficient evidence to support the maturation hypothesis. However, the patterns observed may be the result of a social selection process in which individuals are more likely to enter parenthood at a moment of low criminal involvement in their career. A different explanation of the short-term effect of parenthood on crime and increases in criminal involvement after childbirth may be related to the age at which individuals become parents. The study of Kerr et al. (2011) showed that "off-time" (young) and normative timing parenthood seem to be differently associated with crime. In their study, the older the men were when becoming fathers, the stronger the decline in crime. A different study conducted in the Netherlands (De Goede et al. 2011) for first time parenthood showed similar results: the likelihood of criminal involvement for older fathers is lower compared to the one for younger fathers, and, the younger the age of entering parenthood, the higher the likelihood of offending. Although our study controlled for age effects, we did not further interact fatherhood and age to understand how crime involvement changes around entrance into parenthood for younger or older fathers. It may be that the at-risk individuals in our study (known for experiencing unconventionally ordered transitions) became parents at younger ages when autonomy from their own family of origin is not fully gained and parenthood roles are not properly integrated.

Whereas our findings seem to support the assumption that parenthood leads to changes in crime, the direction of change observed (increase in criminal involvement) is not consistent with the one described by the turning point hypothesis (Sampson and Laub 1993). However, a consideration of the processes explaining observed trends may offer a more nuanced interpretation of our results in the light of this hypothesis. If we consider the role change (becoming a parent) as a determinant of a conforming lifestyle, then our results indeed do not sustain the turning point assumption. However, this role change might influence the manner in which spouses exert their direct social control. Because the presence of a child can affect a romantic union in many ways (e.g., reduced emotional support and attention for the partner), a spouse may decrease levels of social control and reduce bonding, which in turn may lead to changes in daily routines that can be transposed into crime.

The increase in criminal involvement post-childbirth is in line with the pattern described by strain theory, and we can hypothesize that entrance into parenthood might be associated with a sort of stress (Miller and Sollie 1980). Furthermore, it was stated that choosing to resolve strain through crime might depend on the financial aspirations or difficulties of the individuals (Lilly et al. 2002). Accordingly, a straightforward criminogenic reaction to economic strain would then be transposed into engagement in property offenses (Broidy and Agnew 1997; Daly 1998; Giordano et al. 2002, 2011; Wakefield and Uggen 2004). With the exception of Norwegian males, results show only minor increases in the probabilities to commit property offenses. Furthermore, when comparing trends for each individual subgroup analyzed, we observed that a considerable part of the increases in overall 
offending remains unexplained by involvement in property offending. However, before concluding that criminal conduct is not the product of strain resulting only in economic offenses, future studies should focus particularly on employment participation and how this participation diminishes the financial burden related to parenthood. Moreover, other offences generating income (e.g., drug dealing) should also be considered. Increases in crime after childbirth may also be explained by the fact that parenthood causes individuals to spend more time within the family and, as a result, facilitates occurrences of domestic violence. Unfortunately, the available registered data were limited in providing information on domestic violence. Overall, our results suggest that financial strain is not the only possible process explaining the crime-amplifying effects of parenthood.

A specific focus of this study was to identify possible abrupt changes in the daily activities related to entrance into parenthood. As hypothesized by the routine activity theory (Cohen and Felson 1979), a major shift in offending should occur immediately after childbirth, and an overall declining path should follow thereafter. With the exception of high-risk Dutch males, we did not identify a significant shift in offending probabilities in the month of childbirth. Nevertheless, even for the Dutch males, the estimated coefficient for the shift was only marginally significant. Moreover, for all groups analyzed, the postchildbirth period was characterized by increases in probabilities to offend. Similar conclusions can be extracted when analyzing the splines for property offenses, with a note that in this case, no marked shift was evidenced at birth for any of the groups.

Starting from the assumption that the experience of parenthood is different for men and women, we expected to see gender differences in criminal trends (Giordano et al. 2011). Whereas for Dutch males signs of change occurred long before entrance into parenthood (from 5 years before childbirth), the changes in offending for Dutch females seem to be in a closer relationship with parenthood anticipation because declines start approximately 1.5 years before birth. One may think that anticipation and planning for these high-risk females might seem unreal. We argue that this impression is not necessarily accurate because these high-risk females grew up in a contemporary Western society, and even for them, a reasonable level of birth control exists. Thus, a preparation of up to 1 year ahead of a pregnancy is perhaps not unusual. The earlier change among men could also be related to the Dutch criminal justice system, which tends to provide a milder treatment for females (Wartna and Tollenaar 2006). Dutch males may be more aware of the long-term negative consequences of their criminal conduct. However, particularly for high-risk men, it is unlikely that this awareness relates directly to preparation for parenthood. We interpret this awareness more as a maturation process (growing out of crime) for individuals with intense criminal activity in their teenage years. The post-birth period is characterized by gradual increases in the probabilities to offend for both males and females, and, although the magnitude of increase differs by gender, the increase is proportional to the overall involvement in crime for each group (and is lower for females). In the Norwegian elevated-risk sample, both genders display the strongest decline in offending trends approximately 1.5 years before birth. Similarities in the desistance process could be related to the fact that the Norwegian social system ensures stronger gender equality with respect to parenthood (e.g., parental leave obligatory for both males and females, stimulation of female employment through advantageous childcare services). The post-childbirth crime trends in the Norwegian sample show more-visible gender differences. Whereas the analysis for males shows an increasing trend in crime, the probabilities for females to offend show only a minor increase and remain at a lower level compared with the pre-birth period. In other words, for Norwegian elevated-risk females, the beneficial effects of motherhood are visible over the long term, whereas for Norwegian elevated-risk males, the motivation for change is only temporary. Interestingly, a 
previous Norwegian study (Monsbakken et al. 2013) showed that the rebound effect around the first childbirth is stronger for females than for males as in our case. However, we have no particular reason to expect that the patterns should be similar because the sample analyzed by Monsbakken and colleagues (general population) differs from the one in this study (at-risk individuals - with problematic backgrounds and increased risk of recidivism).

With respect to social context differences, elements can be additionally discussed. Prebirth trends for females are relatively similar across countries. However, entrance into parenthood seems to be related to a slightly stronger rebound for high-risk Dutch females. The process of desistance for high-risk males seems to have a different starting momentat least 5 years before childbirth for Dutch respondents, whereas for Norwegian respondents, changes appear approximately 1.5 years before childbirth. With the awareness of considerable state support (Norway provides considerably more advantageous parental packages compared with the Netherlands), elevated-risk males in Norway are less forced to adopt a non-criminal lifestyle to prepare themselves for adult life, including parental responsibilities. Nevertheless, these male differences observed across countries might be the result of unobserved dissimilarities between groups. The institutionalized individuals in the Dutch sample may be a group of more frequent youth offenders who reached their crime peak in adolescence and thereafter gradually move away from crime. The post-birth male trends show no differences across countries, strengthening the evidence that fatherhood does not offer sufficient motivation for change in the long term. In the context of different social benefits across countries (Savolainen et al. 2001), the results for male property offending remain puzzling. Because the Norwegian system is more generous concerning parental benefits (Gauthier 2014), we would not expect increases in property offending rates to be stronger for Norwegian males. A possible explanation for this pattern is that involvement in property crime represents an individual aiming for material success rather than a direct result of poverty.

\section{Limitations of the Study}

Although this study offers new insights into the relationship between parenthood and criminal offending, a number of discussion points and limitations should be addressed. First, a causal association between parenthood and criminal involvement cannot be claimed in this study. However, causal estimation was not a study aim. Without any pretentions of causality, we offered an analysis of specific timings of change in relation to entrance into parenthood and assessed whether the theoretical predictions fit the observable patterns. The strength of our study is that it provides a nuanced picture of what is to be explained and of how well these patterns provide support for the dominant theoretical approaches in the literature.

Second, although the matching samples procedure aimed to create similar groups across countries, we could only match on a limited number of variables, which is most likely typical for comparative studies; nonetheless, the limited number remains an issue. Most likely one of the first variables to be considered in constructing the Norwegian sample was supposed to be youth institutionalization. Unfortunately, we did not have access in the Norwegian data to information on youth rehabilitation programs. For this reason, we matched individuals on other characteristics considered reflective of an at-risk sample. However, although we consider the matching imperfect, the fact that we found reasonably similar patterns in two potentially different at-risk groups, in different contextual settings, indicates a sort of generality in the patterns observed. 
Third, register data used for this study are limited in providing information on qualitative aspects of the family relationship, which might be important for the effect of parenthood on crime. As some authors noted, reduction in crime related to entrance into parenthood should be nuanced by a high-quality relationship (Ganem and Agnew 2007) or assume daily childrearing responsibilities (Yule et al. 2014; Kerr et al. 2011). The rebound found in our study might result from a majority of families not having such qualities. To explain further, additional information on the type of parent-child relationship is needed because for at-risk individuals (men in particular), the parent-child relationship might be a non-ideal one (e.g., parent-child relationship of poor quality or non-existent). Moreover, there is the issue of whether registered crimes correspond to the true crimes committed. It is possible that actual offending drops substantially in the post-birth period but that this is unobserved because the outcome captures only criminal adjudication. A previous study conducted by Kerr et al. (2011) highlighted differences between self-reported and official arrests and found that fatherhood reduced self-reported crime but official arrests remained unrelated to fatherhood. Clearly, future studies should introduce a mixed method design including both self-reports and official registrations on criminal behavior in order to capture 'real' changes in criminal development.

Fourth, in the context of Western societies in which family relationships have become less standardized (Elzinga and Liefbroer 2007), the linkage between parenthood and crime might depend upon relationship configuration (e.g., married, cohabiting or dating the biological father). Unfortunately for this study, only information on marital status was available. Future research should consider a broad range of intimate configurations. Next to this, the gender gap in crime should address elements of legal and social sanctioning such as loss of custody or parental rights, social assistance, housing, or unemployment to obtain a clearer understanding of the processes describing the effects of parenthood on crime. Furthermore, the effect of parenthood on criminal trajectories must be studied in relation with existing cultural norms highlighting the normative ages of entering parenthood (in different social contexts and for each gender) and how at-risk individuals differ from these norms.

Finally, the use of an at-risk sample may be considered a limitation because it is a nonrandom sample, which restrains the possibility to generalize results. For this reason, a replication of a similar design on general population samples is necessary. However, the analysis of disadvantaged groups is common in criminology and has advantages. First, change in offending is most relevant for those having reached a reasonable threshold of offending (Laub and Sampson 2003, p. 22), making at-risk groups of substantive interest. Second, individuals associated with troubled backgrounds, youth misconduct, and delinquency have been later registered as high-risk career criminals (Lynam 1996) and serious offenders (van der Geest and Bijleveld 2008) and represent a serious social and economic problem (Cohen and Piquero 2009). Thus, an understanding of the factors that can lead to a discontinuation of criminal offending in adult life for these individuals is of major importance for criminal policy and practice.

\section{Concluding Remarks}

This study is not the first one to show a rebound in offending after the transition to parenthood. A previous study conducted in Norway on a general population sample showed a similar V-shaped pattern around childbirth (Monsbakken et al. 2013). Several other Western European studies identified comparable rebounds for other life-course 
transitions such as marriage (Lyngstad and Skardhamar 2013; Beijers et al. 2012) and employment (Skardhamar and Savolainen 2014; van der Geest et al. 2015). In contrast to the above-mentioned European studies, some US studies found no rebound in offending after the transition to parenthood (Kreager et al. 2010) or marriage (Laub et al. 1998; Duncan et al. 2006). This discrepancy in results could be explained by cultural differences between the US and Western European contexts. However, a more sober interpretation is that the evidence is too scarce to settle the issue. Our study provides additional support to the notion that timing of change should be investigated more closely.

Taken together with the mentioned European studies, our results indicate that lifecourse transitions are not followed by a decline in offending. The observed decline starts earlier and tends to be limited to a relatively short time interval. This does not necessarily mean that parenthood and other life-course transitions do not affect crime but that the type of causal effect must be considered more closely. Such results suggest that life-course events such as employment, marriage and parenthood do not initiate desistance. However, for a short period, they seem to sustain an ongoing desistance process initiated in a previous phase in life. Another possibility to be considered is whether the counterfactual outcome (not becoming a parent) would have caused an even greater increase in crime. If so, parenthood could still have a negative causal effect on crime, despite the observed rebound. This result could be considered a dampening effect on criminal propensity but not one leading to desistance. Initiation, sustaining and dampening effects might all be causal but reflect different social processes related to timing. An important task of future lifecourse criminological research is to differentiate such processes clearly and to obtain moredetailed empirical work and theoretical specifications of operant mechanisms.

Open Access This article is distributed under the terms of the Creative Commons Attribution 4.0 International License (http://creativecommons.org/licenses/by/4.0/), which permits unrestricted use, distribution, and reproduction in any medium, provided you give appropriate credit to the original author(s) and the source, provide a link to the Creative Commons license, and indicate if changes were made.

\section{References}

Agnew R (1992) Foundation for a general strain theory of crime and delinquency. Criminology 30:47-87 Agnew R (2006) Pressured into crime: an overview of general strain theory. Roxbury, Los Angeles

Beijers JEH, Bijleveld CCJH, van Poppel F (2012) 'Man's best possession': period effects in the association between marriage and offending. Eur J Criminol 9:425-441

Berk R, Brown L, Buja A, George E, Pitkin E, Zhang K, Zhao L (2014) Misspecified mean function regression: making good use of regression models that are wrong. Sociol Methods Res 43:422-451

Bersani B, Laub J, Nieuwbeerta P (2009) Marriage and desistance from crime in the Netherlands: do gender and socio-historical context matter? J Quant Criminol 25:3-24

Billari FC, Liefbroer AC (2010) Towards a new pattern of transition to adulthood? Adv Life Course Res 15:59-75

Bjerk D (2009) How much can we trust causal interpretations of fixed-effects estimators in the context of criminality? J Quant Criminol 25:391-417

Blokland AAJ, Nieuwbeerta P (2005) The effects of life circumstances on longitudinal trajectories of offending. Criminology 43:1203-1240

Broidy L, Agnew R (1997) Gender and crime: a general strain theory perspective. J Res Crime Delinq 34:275-306

Clark M (2012) Generalized additive models. Getting started with additive models in R. Center for Social Research, University of Notre Dame. http://www3.nd.edu/ mclark19/learn/GAMS.pdf

Cohen LE, Felson M (1979) Social-change and crime rate trends: a routine activity approach. Am Sociol Rev 44:588-608 
Cohen MA, Piquero AR (2009) New evidence on the monetary value of saving a high risk youth. J Quant Criminol 25:25-49

Corman H, Noonan K, Reichman NE, Schwartz-Soicher O (2011) Life shocks and crime: a test of the "Turning Point" hypothesis. Demography 48:1177-1202

Cowdery RS, Knudson-Martin C (2005) The construction of motherhood: tasks, relational connection, and gender equality. Fam Relat 54:335-345

Daly K (1998) Women's pathways to felony court: feminist theories of lawbreaking and problems of representation. In: Daly K, Maher L (eds) Criminology at the crossroads: feminist readings in crime and justice. Oxford University Press, New York, pp 135-154

De Goede S, Blokland AAJ, Nieuwbeerta P (2011) Parenthood and crime: the effects of having a first child on criminal career development [Ouderschap en crimineel gedrag: het effect van het krijgen van een eerste kind op de ontwikkeling van crimineel gedrag]. Tijdschrift voor Criminologie 53:3-22

Duncan GJ, Wilkerson B, England P (2006) Cleaning up their act: the effects of marriage and cohabitation on licit and illicit drug use. Demography 43:691-710

Edin K, Kefalas M (2005) Promises I can keep: why poor women put motherhood before marriage. University of California Press, Oakland

Edin K, Nelson TJ, Paranal R (2004) Fatherhood and incarceration as potential turning points in the criminal careers of unskilled men. In: Pattillo M, Weiman D, Western B (eds) Imprisoning America: the social effects of mass incarceration. Russel Sage Foundation, New York, pp 46-75

Elzinga CH, Liefbroer AC (2007) De-standardization of family-life trajectories of young adults: a crossnational comparison using sequence analysis. Eur J Popul-Revue Europeenne De Demographie 23:225-250

Farrington DP, West DJ (1995) Effects of marriage, separation, and children on offending by adult males. In: Hagan J (ed) Current perspectives on aging and the life cycle, vol 4. JAI Press, Greenwich, pp 249-281

Feeney J (2001) Becoming parents: exploring the bonds between mothers, fathers, and their infants. Cambridge University Press, Cambridge

Ganem NM, Agnew R (2007) Parenthood and adult criminal offending: the importance of relationship quality. J Crim Justice 35:630-643

Gauthier AH (2014) Van voorloper tot achterblijver; 100 jaar zwangerschapsverlof in Nederland [From precursor to laggard; 100 years of maternity leave in The Netherlands]. Demos: bulletin over bevolking en samenleving 30(9):1-4

Giordano PC, Cernkovich SA, Rudolph JL (2002) Gender, crime, and desistance: toward a theory of cognitive transformation. Am J Sociol 107:990-1064

Giordano PC, Seffrin PM, Manning WD, Longmore MA (2011) Parenthood and crime: the role of wantedness, relationships with partners, and ses. J Crim Justice 39:405-416

Graham J, Bowling B (1995) Young people and crime. Home Office Research Study, 145, London

Horney J, Osgood DW, Marshall IH (1995) Criminal careers in the short-term: intraindividual variability in crime and its relation to local life circumstances. Am Sociol Rev 60:655-673

Kerr DC, Capaldi DM, Owen LD, Wiesner M, Pears KC (2011) Changes in at-risk American men's crime and substance use trajectories following fatherhood. J Marriage Fam 73:1101-1116

Kiernan K (2004) Unmarried cohabitation and parenthood in Britain and Europe. Law Policy 26:33-55

King RD, Massoglia M, MacMillan R (2007) The context of marriage and crime: gender, the propensity to marry, and offending in early adulthood. Criminology 45:33-65

Kreager DA, Matsueda R, Erosheva EA (2010) Motherhood and criminal desistance in disadvantaged neighborhoods. Criminology 48:221-258

Kruttschnitt C (1996) Contributions of quantitative methods to the study of gender and crime, or bootstrapping our way into the theoretical thicket. J Quant Criminol 12:135-161

Laub JH, Sampson RJ (2003) Shared beginnings, divergent lives: delinquent boys to age 70. Harvard University Press, Cambridge

Laub JH, Nagin DS, Sampson RJ (1998) Trajectories of change in criminal offending: good marriages and the desistance process. Am Sociol Rev 63:225-238

Lilly JR, Cullen FT, Ball RA (2002) Criminological theory: context and consequences, 3rd edn. Thousand Oaks, Sage Publications, CA

Lynam DR (1996) Early identification of chronic offenders: who are the fledgling psychopaths? Psychol Bull 120:209-234

Lyngstad TH, Skardhamar T (2011) Nordic register data and their untapped potential for criminological knowledge. Crime Justice 40:613-645

Lyngstad TH, Skardhamar T (2013) Changes in criminal offending around the time of marriage. J Res Crime Delinq. doi:10.1177/002242781246951 
Maruna S (2001) Making good: how ex-convicts reform and rebuild their lives. American Psychological Association Books, Washington, DC

Massoglia M, Uggen C (2010) Settling down and aging out: toward an interactionist theory of desistance and the transition to adulthood. Am J Sociol 116:543-582

Miller BC, Sollie DL (1980) Normal stresses during the transition to parenthood. Fam Relat 29:459-465

Monsbakken CW, Lyngstad TH, Skardhamar T (2013) Crime and the transition to parenthood: the role of sex and relationship context. Br J Criminol 53:129-148

Osgood DW, Lee H (1993) Leisure activities, age, and adult roles across the lifespan. Soc Leis 16:181-208

Osgood DW, Wilson JK, O’Malley PM, Bachman JG, Johnston LD (1996) Routine activities and individual deviant behavior. Am Sociol Rev 61:635-655

Paternoster R, Bushway S (2009) Desistance and the feared self: towards an identity theory of criminal desistance. J Crim Law Criminol 99:1103-1156

Perelli-Harris B, Kreyenfeld M, Sigle-Rushton W, Keizer R, Lappegard T, Jasilioniene A, Berghammer C, Di Giulio P (2012) Changes in union status during the transition to parenthood in eleven European countries, 1970s to early 2000s. Popul Stud J Demogr 66:167-182

Rhule-Louie DM, McMahon RJ (2007) Problem behavior and romantic relationships: assortative mating, behavior contagion, and desistance. Clin Child Fam Psychol Rev 10:53-100

Ross CE, Huber J (1985) Hardship and depression. J Health Soc Behav 26:312-327

Sampson RJ, Laub JH (1993) Crime in the making: pathways and turning points through life. Harvard University Press, Cambridge

Sampson RJ, Laub JH (2003) Life-course desisters? trajectories of crime among delinquent boys followed to age 70. Criminology 41:555-592

Sampson RJ, Laub JH, Wimer C (2006) Does marriage reduce crime? a counterfactual approach to withinindividual causal effects. Criminology 44:465-508

Savolainen J (2009) Work, family and criminal desistance. Br J Criminol 49:285-304

Savolainen J, Lahelma E, Gauthier AH, Silventoinen K (2001) Parenthood and psychological well-being in Finland: does public policy make a difference? J Comp Fam Stud 32:61-74

Shannon SKS, Abrams LS (2007) Juvenile offenders as fathers: perceptions of fatherhood, crime, and becoming an adult. Fam Soc J Contemp Soc Serv 88:183-191

Skardhamar T, Savolainen J (2014) Changes in criminal offending around the time of job entry: a study of employment and desistance. Criminology 52:263-291

Skardhamar T, Savolainen J, Aase KN, Lyngstad TH (2015). Does marriage reduce crime? a review of research. Crime and Just 44:385-557

Sobotka T (2008) The diverse faces of the second demographic transition in Europe. Demogr Res 19:171-224

Theobald D, Farrington DP (2009) Effects of getting married on offending results from a prospective longitudinal survey of males. Eur J Criminol 6:496-516

Thevenon O (2011) Family policies in OECD countries: a comparative analysis. Popul Dev Rev 37:57-87

Thompson M, Petrovic M (2009) Gendered transitions: within-person changes in employment, family, and illicit drug use. J Res Crime Deling 46:377-408

Thornberry TP, Wei EH, Stouthamer-Loeber M, Van Dyke J (2000) Teenage fatherhood and delinquent behavior. Juvenile Justice Bulletin, Office of Justice Programs-Youth Development Series, NCJ: 178899

Uggen C, Kruttschnitt C (1998) Crime in the breaking: gender differences in desistance. Law Soc Rev 32:339-366

van der Geest V, Bijleveld C (2008) Personal, background and treatment characteristics associated with offending after residential treatment: a 13-year follow up in adolescent males. Psychol Crime Law 14:159-176

van der Geest V, Blokland A, Bijleveld C (2009) Delinquent development in a sample of high-risk youth: shape, content, and predictors of delinquent trajectories from age 12 to 32 . J Res Crime Delinq 46:111-143

van der Geest V, Skardhamar T, Verbruggen J (2015) Changes in offending around official labor market entry: vulnerable youths in transition to adulthood. In: van der Geest V, Blokland A (eds) Routledge handbook of life-course criminology. Routledge, New York

Wakefield S, Uggen C (2004) Having a kid changes everything? the effects of parenthood on subsequent crime. Unpublished article (downloaded Sept. 2013). http://citation.allacademic.com/meta/p_mla_apa_ research_citation/1/0/9/5/6/pages109560/p109560-1.php

Warr M (1998) Life-course transitions and desistance from crime. Criminology 36:183-216

Wartna BSJ, Tollenaar N (2006). Substitution of non-suspended imprisonment in cases of minimal recidivism risk: estimating potential cut backs in prison capacity [Substitutie van onvoorwaardelijke 
vrijheidsstraffen bij gering recidivegevaar: een raming van de te besparen gevangeniscapaciteit]. Wetenschappelijk Onderzoeken Documentatiecentrum, WODC-recidivestudies, Fact sheet 10

Wood SN (2003) Thin plate regression splines. J R Stat Soc Ser B (Stat Methodol) 65:95-114

Wood S (2006) Generalized additive models: an introduction with R. Chapman and Hall/CRC, Boca Raton Yule C, Pare PP, Gartner R (2014) An examination of the local life circumstances of female offenders: Mothering, illegal earnings, and drug use. Brit J Criminol 55:248-269

Zimmerman TS, Haddock SA, Ziemba S, Rust A (2001) Family organizational labor: who's calling the plays? J Fem Fam Ther 13:65-90

Zoutewelle-Terovan M, van der Geest V, Liefbroer AC, Bijleveld C (2012) Criminality and family formation: effects of marriage and parenthood on criminal behavior for men and women. Crime Delinq. doi:10.1177/0011128712441745 